\title{
LETTERS
}

\section{Using thermography responsibly}

CMAJ recently published an article about the development of thermography by my father, Dr. Ray N. Lawson. ${ }^{1}$ It is unfortunate that the article had to begin with a long paragraph that framed thermography in a very negative light. In the final paragraph, an unattributed pejorative reference in quotation marks apparently came from a mainstream television news organization, rather than a respected scientific source.

I think it should be known that in addition to pioneering thermography, my father also came to appreciate its limitations at an early date. He used it responsibly, as an adjunctive procedure to other nonintrusive methods. When he opened his private breast cancer clinic in Westmount, in the early 1970 s, he relied primarily on the Senographe, a substantial advancement in mammography, which had been developed in France. My father recognized the potential of the Senographe at an early date and he had one of the first such machines (perhaps the first) in clinical use in North America.

Unfortunately, in the years subse- quent to my father's retirement, other practitioners irresponsibly overpromoted the benefits of thermography. This persisted for decades, with apparent impunity, until there was a negative backlash accompanied by sensational coverage in the national mainstream news media. It is unfortunate that related negative comments had to find their way into the CMAJ article.

It is my hope that my father will be remembered for his major contributions. In addition to his efforts to harness Cold War technology for use in medicine, he was a surgeon practitioner who had the ability to recognize the direction his area of practice would take in the future. His work was influential in moving it forward.

\section{Joseph R. Lawson BSc MBA}

Toronto, Ont.

Cite as: CMAJ 2017 July 10;189:E917. doi: $10.1503 /$ cmaj. 733213

\section{Reference}

1. Fraser J. Hot bodies; Cold War: the forgotten history of breast thermography. CMAJ 2017;189:E573-5.

Competing interests: The author is the son of Dr. Ray N. Lawson. 